\title{
ANÁLISE DO TRABALHO EM EQUIPE MULTIPROFISSIONAL PARA AÇÕES DE ALIMENTAÇÃO E NUTRIÇÃO NA ATENÇÃO BÁSICA
}

\author{
ANALYSIS OF THE MULTIPROFESSIONAL TEAMWORK FOR ACTIONS \\ REGARDING DIET AND NUTRITION IN PRIMARY HEALTH CARE
}

\begin{abstract}
Rayane Jeniffer Rodrigues Marques ${ }^{1}$ [0000-0002-9099-850x], Katiusse Rezende-Alves² 3393-8567], Caroline Schilling Soares ${ }^{3}$ [0000-0002-2454-3435], Kelly Alves de Magalhães ${ }^{1}$ 5561], Larissa Ferraz Morelli ${ }^{4}$ (D) [0000-0001-6780-831x]. Aline Cristine Souza Lopes ${ }^{4}$

${ }^{1}$ Prefeitura de Belo Horizonte, Minas Gerais, Brasil.

${ }^{2}$ Universidade Federal de Viçosa, Departamento de Medicina e Enfermagem, Viçosa, Minas Gerais, Brasil.

${ }^{3}$ Prefeitura de Belo Horizonte, Secretaria Municipal de Saúde, Belo Horizonte, Minas Gerais, Brasil.

${ }^{4}$ Universidade Federal de Minas Gerais, Departamento de Nutrição, Belo Horizonte, Minas Gerais, Brasil.<alinelopesenf@gmail.com>
\end{abstract}

Resumo $\mathrm{O}$ estudo analisou o processo de trabalho de profissionais de um Núcleo Ampliado de Saúde da Família na Atenção Básica na implantação de atividades educativas coletivas de promoção da alimentação adequada e saudável. Foi utilizado o método de abordagem qualitativa, com base em um estudo-piloto de um ensaio comunitário controlado e randomizado, com a participação de seis profissionais. As entrevistas seguiram roteiro semiestruturado. A análise de conteúdo foi empregada para desvelar significados das falas dos participantes. Emergiram três categorias: integração da equipe como eixo propulsor do processo de trabalho; educação libertadora e comprometimento como eixos norteadores para a implantação das atividades coletivas de alimentação saudável; e desafios à implementação das atividades educativas de alimentação saudável. Os resultados demonstram que a metodologia de grupo proposta pelo Ministério da Saúde é uma boa estratégia para a organização e condução do processo de trabalho. Ademais, favoreceu a integração de forças de trabalho de profissionais de distintas categorias, resultando no fortalecimento da equipe no exercício da interdisciplinaridade e na criação de espaços coletivos de trocas, de cuidado e de empoderamento dos indivíduos assistidos.

Palavras-chave promoção da saúde; educação em saúde; alimentação; atenção primária à saúde
Abstract This The study assessed the work process of the professionals of an Extended Health of the Family Center (Núcleo Ampliado de Saúde da Família, in Portuguese) in Primary Health Care regarding the establishment of collective educational activities for the promotion of a healthy and proper diet. We used the qualitative approach method, based on a pilot study of a randomized and controlled community trial, with the participation of six professionals. The interviews followed a semi-structured script. Content analysis was employed to reveal the meanings of the speeches of the participants. Three categories emerged: integration of the team as the driving force of the work process; liberating education and engagement as the guiding axes for the implementation of collective activities regarding healthy eating; and challenges to the implementation of educational activities on healthy eating. The results show that the group methodology recommended by the Brazilian Ministry of Health is a good strategy for the organization and management of the work process. Moreover, it boosted the integration of the work force of professionals from different categories, resulting in the strengthening of the team in the practice of interdisciplinarity and in the development of collective spaces for exchanges, care and empowerment of the assisted individuals.

Keywords promotion of health; education in health; diet; primary health care 


\section{Introdução}

A alimentação de baixa qualidade é um dos principais fatores de risco modificáveis para as doenças crônicas não transmissíveis (DCNTs) que são a principal causa de morbimortalidade no mundo. Para o enfretamento desse cenário epidemiológico, tem-se o modelo assistencial da Atenção Básica em Saúde (ABS) brasileira. Tal modelo é centrado na Estratégia de Saúde da Família (ESF) e matriciado pelo Núcleo Ampliado de Saúde da Família na Atenção Básica (NASF-AB). O ABS é privilegiado, pois favorece o desenvolvimento de processos de trabalho voltados para ações de promoção da saúde, como as de promoção da alimentação adequada e saudável (PAAS) (Brasil, 2008; Brasil, 2017; Mendonça e Lopes, 2012).

A PAAS constitui uma das diretrizes da Política Nacional de Alimentação e Nutrição (PNAN) (Brasil, 2013) e um eixo estratégico da Política Nacional de Promoção da Saúde (PNPS) (Brasil, 2010). Ela envolve a garantia do direito básico do ser humano à alimentação com respeito aos aspectos biológicos e socioculturais e à sustentabilidade do meio ambiente (Brasil, 2013).

Entretanto, a magnitude das DCNTs, associada à baixa adesão à alimentação adequada e saudável pela população, convoca gestores e profissionais de saúde a refletirem criticamente sobre a organização e o desenvolvimento de processos de trabalho capazes de impactar positivamente a melhoria das condições de saúde e alimentação.

Por esta razão, o Ministério da Saúde lançou o 'Instrutivo - Metodologia de Trabalhos em Grupo para Promoção de atividades de Alimentação Adequada e Saudável na Atenção Básica', que propõe uma metodologia de grupos para ampliar e reforçar o trabalho de PAAS na ABS (Brasil, 2016a). As atividades educativas de PAAS planejadas em equipe podem produzir ações mais abrangentes e efetivas, relacionadas à educação em saúde dos usuários, como podem contribuir para a educação permanente dos profissionais envolvidos.

O uso de uma metodologia que auxilia na organização do processo de trabalho pode favorecer a integração entre profissionais e o fortalecimento da equipe na execução de atividades educativas de PAAS. A interposição de diferentes olhares possibilita que se alcance a interdisciplinaridade. Além disso, são escassos os estudos que avaliam o processo de implementação e qualificação das equipes que atuam na $\mathrm{ABS}$, especialmente sobre a temática da PAAS.

Dessa forma, investigar uma temática relevante para a saúde coletiva e para a promoção da saúde pode contribuir com informações mais específicas e aprofundadas acerca da implementação de atividades de PAAS e 
da qualificação de equipes para as atividades educativas propostas pelo Instrutivo. Nesse contexto, este estudo propôs-se a analisar o processo de trabalho em equipe de profissionais do NASF-AB na implantação de atividades coletivas de PAAS.

\section{Métodos}

Trata-se de uma pesquisa qualitativa, cujo ponto de partida é um estudopiloto de um ensaio comunitário controlado e randomizado, cujo objetivo foi o de avaliar a implantação e a efetividade das atividades coletivas de PAAS na ABS.

Antes de iniciar o ensaio comunitário, foi realizado um estudo-piloto para verificar a aplicabilidade dos instrumentos e da metodologia proposta (Richardson et al., 1999). O estudo foi conduzido em um distrito sanitário dotado de 14 Unidades Básicas de Saúde (UBS), 56 equipes de ESF e oito polos do NASF-AB.

Com a finalidade de adequada execução, o estudo-piloto ocorreu em quatro fases: Oferta de atividade de educação permanente para os profissionais da ABS com vistas à aplicação das atividades coletivas de PAAS; Linha de base para investigação quantitativa do perfil dos usuários participantes das atividades coletivas; Acompanhamento e apoio ao desenvolvimento das atividades coletivas de PAAS realizadas pelos profissionais da ABS por meio da tutoria; Avaliação qualitativa da implantação das atividades coletivas de PAAS, que constituiu o foco deste artigo.

Adotou-se como critério de inclusão: ser profissional de um dos polos NASF-AB da unidade de saúde em questão e ter participado integralmente do desenvolvimento do estudo-piloto ou ser gestor do NASF-AB no distrito. Dessa forma, foram elegíveis os seis profissionais de um dos polos NASF-AB (nutricionista, fonoaudióloga, farmacêutica, terapeuta ocupacional, assistente social e fisioterapeuta), além da gestora do distrito e uma residente em terapia ocupacional. Ocorreram duas perdas: uma assistente social e um fisioterapeuta.

As seis participantes eram mulheres (nutricionista, fonoaudióloga, farmacêutica, terapeuta ocupacional e uma residente em Terapia Ocupacional e a gestora distrital do NASF-AB). O tempo de atuação em ABS foi de, aproximadamente, cinco anos e possuíam experiência em: atendimentos individuais, visitas domiciliares, atividades burocráticas, atividades coletivas de educação em saúde e reuniões com destaque para o matriciamento das equipes da ESF. 


\section{Atividades coletivas de PAAS}

As atividades desenvolvidas foram pautadas no livro "Instrutivo - Metodologia de trabalhos em grupo para promoção de atividades de alimentação adequada e saudável na Atenção Básica". Foram utilizados como materiais de apoio os livros "Desmistificando dúvidas sobre alimentação e nutrição" (Brasil, 2016b) e "Na cozinha com as frutas, legumes e verduras" (Brasil, 2016c). Além dessas obras, empregaram-se os materiais educativos diário de bordo, painel e folders. Esse conjunto de materiais faz parte de um esforço do Ministério da Saúde de propor estratégias metodológicas, pautadas em evidências científicas, com o objetivo de instrumentalizar os profissionais para o desenvolvimento de atividades coletivas de PAAS mais efetivas e alinhadas às políticas públicas.

As atividades coletivas de PAAS foram desenvolvidas no período de setembro de 2015 a julho de 2016 e incluíram a realização das seguintes oficinas: Quem somos nós?; O que é saúde para você?; Tempestade de Dúvidas; Laboratório dos gostos; Planejando a minha alimentação; Alimentação saudável: por onde começar? A balança das escolhas; Saboreando uma alimentação adequada e saudável; ações no ambiente Festival gastronômico; Nossas Escolhas Alimentares; Alimentação Saudável: por quê? e Alimentação saudável hoje e sempre. Além das oficinas, houve a elaboração de painéis temáticos, tais como Quem somos nós?; O que é saúde para você?; Para escolhas alimentares mais saudáveis. Para o desenvolvimento, os profissionais receberam impressos o Instrutivo, o diário de bordo, o painel e os folders; os demais livros foram disponibilizados por e-mail.

Para a execução das atividades coletivas de PAAS, a equipe do NASF-AB contou com tutoria presencial e não presencial. A presencial compreendeu três visitas à unidade para o acompanhamento das atividades e auxílio no planejamento dos encontros. A tutoria virtual ocorreu por contato telefônico e em mídias sociais, com intuito de possibilitar a proximidade com os profissionais e discussão sobre possíveis dificuldades.

\section{Coleta e análise de dados}

A coleta de dados ocorreu entre junho e julho de 2016 por meio de entrevistas com roteiro semiestruturado, elaborado pelas pesquisadoras. $\mathrm{O}$ roteiro incluiu questões norteadoras sobre a implantação das atividades propostas, a metodologia utilizada e sua aplicabilidade no serviço, inclusive por outras categorias profissionais, além do nutricionista.

Todas as entrevistas foram gravadas em dia, horário e local escolhidos de acordo com a disponibilidade dos entrevistados e transcritas, concomitantemente à sua realização, por uma das pesquisadoras. Posteriormente, 
foram submetidas à análise de conteúdo, que consiste em identificar os núcleos de sentido que compõem a comunicação e envolve três momentos: pré-análise, exploração do material, tratamento dos resultados, inferência e interpretação (Bardin, 2009; Minayo, 2013).

Para melhor compreender o objeto de estudo, os dados foram organizados, com base no corpus das entrevistas, nas seguintes categorias: Integração da equipe NASF-AB como eixo propulsor do processo de trabalho; Educação libertadora e comprometimento como eixos norteadores para a implantação das atividades coletivas de PAAS; e Desafios à implementação das atividades educativas de PAAS.

$\mathrm{O}$ estudo ocorreu dentro dos padrões éticos exigidos pela Resolução $\mathrm{n}^{\circ}$ 466/2012 do Conselho Nacional de Saúde e obteve aprovação pelos Comitês de Ética em Pesquisa da Universidade (CAAE:56698716.2.0000.5149) e da Prefeitura do município (CAAE: 56698716.2.3001.5140). O gestor e os profissionais da ABS foram colocados a par dos objetivos e métodos da pesquisa e, após esclarecimento de dúvidas, assinaram o termo de consentimento livre e esclarecido. Para fins de sigilo na apresentação dos resultados, os participantes foram codificados com as letras E, seguidas do número de sequência das entrevistas.

\section{Resultados e discussão}

\section{A integração da equipe NASF-AB como eixo propulsor do processo de trabalho}

Estar em equipe e desenvolver atividades de caráter coletivo é uma das prioridades do trabalho dos profissionais do NASF-AB, o que demanda uma organização do processo de trabalho de forma conjunta. As reuniões de equipe representam espaços de integração e alinhamento do processo de trabalho, incluindo o planejamento das atividades do estudo-piloto, bem como atividades de educação permanente. Assim, parte da carga horária desses profissionais foi destinada à participação em reuniões. Todavia, um aspecto que diferenciou a equipe estudada foi a união e o comprometimento em torno do processo de trabalho, buscando planejar e aprimorar as atividades coletivas de PAAS propostas.

Geralmente, a gente tem uma reunião de núcleo uma vez por mês. Aí, nessas reuniões, a gente afinava alguma coisa, mostrava o cronograma. Foi muito tranquilo, não teve nenhum problema. (E3) 
A gente $[\ldots]$ organiza encontros bimensais com cada categoria onde a gente discute fluxo, propõe criação de protocolos, chama o profissional [...] da própria rede para capacitação dos profissionais do NASF. Nós temos também as reuniões gerais [...] Eu passo questões relacionadas a fluxos. Nessa reunião, a gente traz, por exemplo, profissional que fez um mestrado, então vem apresentar o seu trabalho. Discute protocolos que a Secretaria coloca [...]. Alguns não são para dar sugestão, mas são para serem usados. Então, essa reunião com todos os profissionais juntos [...] eu entendo como um espaço de educação permanente também. (E6)

As reuniões configuraram momentos de encontros, de estar junto para identificar lacunas de conhecimento e inseguranças a serem superadas com base na relação mútua e interdisciplinar de ajuda. Assim, o trabalho colaborativo entre os profissionais tornou-se uma ferramenta que auxiliou nos processos de educação permanente em saúde e no fortalecimento da equipe, refletindo positivamente na integração, na abrangência e na efetividade das atividades coletivas de PAAS (Brasil, 2014b; Saporetti, Miranda e Belisário, 2016).

Pela análise da organização das atividades coletivas de PAAS propostas pelo estudo-piloto, observou-se que a força de trabalho foi aplicada de forma integrada e compartilhada e que a equipe se esforçou para estruturar o processo de trabalho nos moldes da integralidade e da interdisciplinaridade. O apoio mútuo entre os profissionais do NASF-AB e destes com os da ESF permeou toda a implementação das atividades educativas, como pode ser visto a seguir:

Foi fácil (desenvolvimento das atividades), porque nossa equipe é muito boa, a gente tem uma sintonia boa. A gente está sempre trabalhando em equipe. Faz atendimentos compartilhados, grupos - a gente tem sempre esse costume de chamar para participar (envolver outros profissionais) (E3).

Esse núcleo [...] é um núcleo dos sonhos mesmo, a gente é muito equipe, então, da mesma forma com que a gente fazia o grupo tabagismo em equipe, a gente faz outros grupos, a gente também não teve problema nenhum, em dividir. (E4)

[...] todos os grupos que a gente tem, todos nós participamos de alguma forma, mesmo que seja um encontro pontual. (E5)

Essa parte também, assim, de material, a gente conseguiu, cada uma ajudando um pouco. Teve a participação tanto da equipe de Saúde da Família até da coordenadora do NASF do Distrito. Teve uma integração muito bacana entre os profissionais. (E2) 
Para um real trabalho em equipe, é necessário que os trabalhadores tenham sentimento de pertencimento, ou seja, se sintam parte da equipe. Também é fundamental uma boa comunicação, vínculo e cooperação entre os integrantes, assim como compromisso, corresponsabilidade e momentos de partilha, elementos que tornam possível o aprendizado mútuo (Costa et al., 2014; Fortuna et al., 2005). Todos esses aspectos constituem um recurso importante para o desenvolvimento da educação permanente no cotidiano de trabalho.

Os fragmentos de falas anteriores também evidenciaram que o vínculo desenvolvido entre os profissionais, apesar de suas singularidades expressas, por exemplo, em maneiras diferentes de pensar e agir, representou ferramenta de trabalho importante no fortalecimento da colaboração interdisciplinar (Matuda et al., 2015). Esses aspectos também diferenciaram a condução do processo de trabalho e a produção de resultados pela equipe estudada.

\section{Educação libertadora e comprometimento como eixos norteadores para a implantação das atividades coletivas de PAAS}

A equipe do NASF-AB analisada envolveu-se e comprometeu-se com a proposta de implantação das atividades coletivas de PAAS. Esse engajamento pode ser identificado pela assiduidade ao cronograma das atividades, leitura do Instrutivo e dos demais materiais com antecedência necessária para o adequado planejamento das atividades. Este, por sua vez, incluía a divisão das tarefas e dos responsáveis por cada atividade, conforme a categoria profissional e afinidade com o tema, além da preparação dos materiais necessários para cada atividade. As tarefas mencionadas eram adaptadas, quando necessário, com o intuito de viabilizar o desenvolvimento sem comprometer sua proposta original.

Festival Gastronômico, eu lembro que alguém propôs alguma coisa na hora lá, e ela [nutricionista]: - Não! Temos que seguir à risca porque é o projeto, como a gente está desenvolvendo ele tem que seguir à risca para depois a gente repensar. (E6)

Metodologias que auxiliam a promover o envolvimento e o comprometimento dos profissionais da ABS com os processos de trabalho em equipe e com a promoção da saúde constituem importantes recursos no cuidado integral aos usuários. Na implantação das atividades coletivas de PAAS, as equipes envolvem-se com o desenvolvimento de atividades de educação em saúde. Esse engajamento favorece o empoderamento e o protagonis- 
mo dos usuários na adesão às mudanças necessárias à saúde mediante a socialização, a integração, o apoio psíquico, as trocas de experiências e a construção do vínculo e da aprendizagem coletiva (Brasil, 2014a).

Segundo os relatos dos participantes, embora o enfoque das atividades propostas no Instrutivo fosse voltado para a alimentação, as atividades poderiam ser aplicadas por outros profissionais da área da saúde, além dos nutricionistas. Tal possibilidade foi concretizada em função da metodologia sugerida pelo Instrutivo, com o detalhamento de cada atividade, que serviu de guia para o desenvolvimento de cada etapa. Ademais, cada categoria profissional pôde contribuir com o seu conhecimento específico, agregando mais experiências e saberes à temática da alimentação. A fala de uma das terapeutas ocupacionais expressa isto:

\begin{abstract}
Ah, eu não tive dificuldade. Eu li o manual. [...] A gente tentou colocar um pouquinho assim, da especialidade, mas eu acho que tudo é aplicável a qualquer especialidade, ficou bem tranquilo. [...] Eu acho que a linguagem é, foi muito adequada, a forma de, daquele livrinho, de preparar o grupo e tudo, está tranquilo. (E3)
\end{abstract}

O Instrutivo propõe-se a fornecer suporte técnico-científico e prático para orientar as mudanças nas práticas de saúde pelo uso de metodologias diferenciadas de trabalho em grupo voltadas para a PAAS. Apesar de focar especificamente na alimentação, ele respalda qualquer profissional da ABS e gestores no planejamento, bem como no desenvolvimento de atividades coletivas (Brasil, 2016a). Além disso, a abordagem adotada no Instrutivo está alinhada à proposta de atuação integrada entre as equipes da ESF e do NASF-AB, proporcionando o trabalho interdisciplinar (Brasil, 2014b).

No estudo-piloto, houve a participação de profissionais do NASF-AB e das ESF, o que, geralmente, não ocorre no cotidiano do trabalho do Distrito Sanitário. Evidencia-se, mais uma vez, o engajamento das equipes e o potencial da proposta para ser aplicável aos serviços. Tais resultados sugerem que as atividades coletivas de PAAS propostas no Instrutivo podem contribuir para a integração profissional e para a efetividade na realização de atividades de educação em saúde na ABS.

Teve a participação tanto da equipe de Saúde da Família, do Centro de Saúde, até da coordenadora do NASF também, do Distrito. Teve uma integração muito bacana entre os profissionais. (E2) 
A fala da entrevistada indica que a interdisciplinaridade e a horizontalidade, eixos em que se pauta a metodologia do Instrutivo, permeavam as relações de troca e o diálogo ao longo das atividades. A integração dos profissionais da ABS é essencial para a condução eficaz do processo de trabalho e vivenciar atividades educativas grupais tem ajudado na mudança de postura desses profissionais em relação à forma como desenvolvem atividades educativas. Ao se envolverem e compartilharem saberes, não se limitam à simples exposição ou imposição de conteúdo, o que contribui para aumentar o interesse e a participação dos usuários e, consequentemente, melhorar a adesão às atividades (Queiroz et al., 2016).

A horizontalidade pode ser observada durante a execução das atividades pelas atitudes dos profissionais, que não se colocavam como detentores do conhecimento. Pelo contrário, junto com os participantes, foram construindo e reconstruindo saberes. Ressalta-se que a escuta foi a base do processo de cuidar, empoderar e dar autonomia aos usuários, a ponto de perceberem que são agentes capazes de modificar suas próprias atitudes e crenças.

E uma coisa que eu achei interessante é que muitas ações davam oportunidade de a gente ouvir eles. Aquela que eles fizeram o boneco, os desenhos, eu achei muito interessante a gente conseguir ver a visão deles, o que eles pensam, ouvir o que eles têm a dizer sobre o assunto e sobre outras questões que surgem. (E2).

Eles veem que eles podem ser agentes de transformação, (...) muitos falaram: Ah, eu tomo isso; -Ah, eu como isso, está errado; -Nossa! Como é que tem esse tanto de açúcar na coca-cola? Então, eles iam elaborando e, no final, vão preparar o próprio alimento. (E2)

Porque é uma coisa, essa questão do grupo como um momento de conhecimento vertical. É difícil para o usuário porque, às vezes, não é isso que ele está precisando no momento. Ele precisa ser ouvido, precisa de troca, precisa de uma discussão e, às vezes, é sofrido até para a gente, porque a gente não domina tudo. Então você fica: - Ah, meu Deus! Eu tenho que passar o conhecimento, tenho que ensinar, tenho que educar. E se eles falarem de mim no grupo? Significa que eu não fui um bom profissional, eu não conduzi bem. Então, eu acho que quando é assim, essa forma horizontal torna tudo mais tranquilo e mais prazeroso para os dois lados. (E2)

Os sistemas de saúde têm como desafio incorporar o paradigma sanitário em construção. Este envolve a produção de saberes e práticas de diferentes setores sociais e disciplinas. Então, nesse contexto, a prática fundamentada na horizontalidade e flexibilidade nas decisões, preceitos que estão em con- 
sonância com tal paradigma, favorece o atendimento das necessidades dos indivíduos e comunidades, divisando os conceitos de qualidade de vida, promoção da saúde e de cuidado no processo de viver, ser saudável e adoecer (Erdmann et al., 2006).

A horizontalidade parece favorecer mais ao cuidado do que a abordagem vertical, já que esta, centrada no modelo biomédico, tem gerado baixa vinculação e adesão dos usuários aos programas e tratamentos, além da frustração dos profissionais. A abertura ao usuário e ao trabalho multiprofissional constituem estratégias para tornar as atividades de educação em saúde espaços de diálogo e de construção compartilhada do conhecimento (Alves, Boehs e Heidemann, 2012; Borges e Porto, 2014; Mendonça e Nunes, 2014).

Um exemplo da potência da construção compartilhada de saberes foi o Festival Gastronômico, atividade recomendada pelo Instrutivo, que busca estimular o preparo e o consumo de preparações culinárias saudáveis. Cada usuário ou equipes (formadas por amigos, vizinhos etc.) com até quatro pessoas preparavam um prato para ser oferecido no Festival (Brasil, 2016a). A integração e o envolvimento dos usuários na atividade foram evidenciadas pela fala de uma das profissionais.

Achei interessante o Festival Gastronômico que até no encontro anterior eles ficavam assim: - Mas como é que tem que ser a receita? Tinham um pouquinho de dúvidas assim: - Ah, pode colocar isso, ah, não pode colocar aquilo? Eles só queriam perguntar, mas o legal foi que eles se envolveram, então, eles perguntaram, eles queriam saber... Eles: - Ah, pode fazer em dupla, pode ser separado? Foi muito bacana porque motivou mesmo. Achei que foi uma ideia legal. (E2)

A realização do Festival Gastronômico mostrou que atividades educativas coletivas favorecem a educação libertadora, ideário metodológico de Paulo Freire, que considera o contexto social e cultural, proporciona o diálogo, a escuta qualificada, o vínculo entre profissionais e usuários e o empoderamento e a autonomia dos participantes. Dessa forma, rompe com o tradicional modelo biomédico de transmissão vertical do conhecimento (Alves, Boehs e Heidemann, 2012; Borges e Porto, 2014; Mendonça e Nunes, 2014).

A integração e o envolvimento de profissionais e dos usuários no Festival Gastronômico deixou isso claro, pois, desde a preparação, os usuários faziam perguntas e mostravam-se interessados. Com isso, uma das profissionais propôs premiar os pratos vencedores com mudas de plantas. Foram várias as evidências de compartilhamento de ideias de conhecimentos, de forma que, mesmo após o término da atividade, os usuários envolvidos 
continuaram a trocar receitas culinárias e mudas de plantas alimentícias não convencionais (PANCs).

A premiação foi mudas de orégano, manjericão [...]. Eu sei que o orégano fez sucesso, todo mundo queria a muda do orégano e aí essa pessoa que ganhou está até hoje fazendo mudinha para dar para o pessoal do grupo. (E3)

Como uma das ações propostas, foi montado um painel de receitas culinárias e mesmo após a finalização do estudo-piloto, o grupo continuou utilizando o painel.

Eles trocam, trocam receitas, trocam mudinhas. Direto eles estão levando alguma coisa no grupo para compartilhar. Isso também eu achei que foi legal do projeto, a questão do painel de trocar receitas. (E3)

A valorização do saber popular pode favorecer a realização de ações mais participativas ao oferecer ao usuário abertura para compartilhar aquilo que faz parte de seu cotidiano. Desta forma, ele é colocado como sujeito ativo no processo de transformação de sua realidade e vida. Ressalta-se que o intercâmbio de experiências entre indivíduos em situação de vida comum é uma das formas de promover empoderamento pelo processo mútuo de ensinar e aprender (Alves, Boehs e Heidemann, 2012; Borges e Porto, 2014; Mendonça e Nunes, 2014).

Um fator potencializador para a implantação das atividades coletivas de PAAS, mas que também pode ter sido uma limitação para sua avaliação, foi o fato do grupo de usuários já existir há sete anos, denotando forte presença de vínculo com os profissionais e de continuidade do cuidado. Tais características, possivelmente, contribuíram para a adesão, desenvolvimento das atividades e seus resultados, demonstrando ter sido esse um cenário favorável à implantação e avaliação do estudo-piloto.

É um grupo superdiferente, [...] tem mais de sete anos e tem um público que, desde o início, frequenta. Então, eles são bem fiéis mesmo ao grupo. Vai uma média [...] de 15 a 20 participantes. A frequência é ótima, a pontualidade é que, às vezes, não é boa [...]. Sempre tem um que chega no final, tem um que tem que sair mais cedo para buscar o neto, para fazer alguma coisa. Então, tem umas particularidades, mas no geral, [...] 70\%, 80\% chega no horário. (E3) 
Os resultados deste estudo também mostraram que o diálogo interdisciplinar e as práticas colaborativas foram aspectos-chave para a integração entre as equipes de ABS, contribuindo na organização do seu processo de trabalho e no desenvolvimento de uma postura proativa que atua em uma lógica diferenciada. Além disso, o olhar humanizado e o estabelecimento de vínculo foram fundamentais para o cuidado continuado ao dar suporte às relações de troca de experiências que foram sendo desveladas.

\section{Desafios à implementação das atividades educativas de PAAS}

O desenvolvimento das atividades educativas de PAAS foi avaliado como positivo pelos participantes; entretanto, alguns desafios foram assinalados; é válido analisá-los, visto que os profissionais devem estar atentos a esses pontos durante a implementação de atividades de educação permanente e de educação em saúde.

Os principais desafios elencados foram dois: a abordagem teórica sobrepujando a prática na atividade de educação permanente e a escassez de recursos materiais disponibilizados pela unidade de saúde para o desenvolvimento das oficinas. Os relatos a seguir revelam que, apesar da atividade de educação permanente ter sido planejada e executada baseada na metodologia problematizadora, ela ainda reproduziu metodologias tradicionais de ensino marcadas por enfoque teórico, excesso de conteúdo e distanciamento das vivências práticas, tornando as ações fragmentadas, segundo o olhar de alguns participantes.

Oh, eu achei que, às vezes, explorou muito a teoria e não tanto as oficinas em si. Eu acho que poderia ter sido mais a oficina. Ter dado uma introdução um pouco mais rápida e ter abordado as oficinas, porque, efetivamente, é o que a gente vai fazer na prática. (E4)

Eu acho que seria interessante aplicar mais dinâmicas. (E2)

Quando você faz, você visualiza o que é esperado. Então eu achei que foi válido, mas foi muito teórico. (E6)

Às vezes, são poucos encontros, aí é muito conteúdo. Às vezes, muito conhecimento para um encontro só e para um projeto que é novo para todo mundo ali. E, às vezes, pode ser muito diferente da realidade que aquelas pessoas conhecem. (E2)

Eu fiquei pensando que poderia ter uma primeira sensibilização para ver quem ia se interessar de aplicar e depois quem se interessasse ter mais encontros mesmo, para a gente vivenciar mais o projeto. (E5) 
Esses elementos destacados como negativos têm sido encontrados em estudos denotando que, embora seja intenção avançar na abordagem problematizadora, estruturada na ação-reflexão-ação, a execução de atividades de educação permanente, em alguns casos, ainda apresenta restrições (Miccas e Batista, 2014). Estas limitações estão relacionadas à pouca adequação das ações de educação permanente com a realidade e recursos dos serviços, à escassa integração entre instituições de ensino e serviços, bem como à restrita utilização de pedagogias inovadoras que visem ao desenvolvimento do pensamento reflexivo (Campos, Sena e Silva, 2017). Estudos (Miccas e Batista, 2014; Campos, Sena e Silva, 2017) mostraram que há dificuldades conceituais com a educação permanente e sua aplicação nos contextos dos serviços. É comum que ela seja compreendida como educação continuada e baseada em ações pontuais, fragmentadas e na metodologia tradicional de ensino.

Outro aspecto relatado foi a inexistência de recursos financeiros destinados à aquisição de materiais para as atividades educativas coletivas de PAAS, o que onerou os profissionais que disponibilizavam recursos próprios:

Então, eu saí daqui, eu passei em uma floricultura que tem ali, eu gastei uma grana, comprei corrente, comprei os pratos, comprei haste, comprei tudo [...]. Minha casa não tem miojo, graças a Deus! Eu tive que comprar o miojo no supermercado... Eu tive que arrumar uma cesta, eu tive que comprar uma manga, eu tive que comprar um pedaço de melancia, assim, bem ou mal, você gasta dinheiro. [...] Comprei gergelim, o sal, o pacotinho para embalar, imprimi receita e tal. (E1)

Além disso, foram enfrentados problemas com o funcionamento de equipamentos e com a inadequação do espaço disponível para as atividades coletivas de PAAS.

O único mais difícil foi a questão do material, precisava do datashow e do computador e a gente conseguiu, mas, na hora, a gente não conseguiu ajustar o datashow, então a imagem ficou meio borrada [...] dava para ver, mas o som estava um pouco baixo, então eles (usuários) não viram tão bem assim. $\mathrm{O}$ ambiente que a gente tinha para fazer era uma sala um pouco clara, então não reproduziu tão bem. (E5)

Não é incomum que atividades de educação permanente sejam permeadas por dificuldades de infraestrutura material, gestão e recursos humanos. Tais problemas ocorrem, em parte, devido à falta de continuidade nos investimentos e de comprometimento dos gestores na instituição de polos de educação 
permanente em saúde. Os polos facilitam a implementação e gerenciamento das atividades e atuam como espaços de diálogo e articulação entre atores dos serviços e das instituições formadoras. Uma vez instituídos, podem ser identificadas as necessidades de educação permanente, bem como construídas estratégias e políticas de formação e aperfeiçoamento (Miccas e Batista, 2014).

Este estudo teve como limitação o fato de ter se preocupado com a extração de significados de fenômenos relacionados ao contexto de trabalho dos profissionais de saúde por meio da análise de conteúdo. A busca de significados manifestos e latentes pode levar o pesquisador a incorrer no risco de extrapolar o que está posto no discurso transcrito. A fim de minimizar tais interferências, o estudo foi revisado por pesquisador não envolvido com o desenvolvimento do projeto.

Por fim, os resultados deste estudo podem contribuir com profissionais da ABS e gestores com informações úteis acerca do processo de trabalho e de implantação e qualificação das equipes no desenvolvimento de atividades educativas coletivas de PAAS propostas pelo Instrutivo.

\section{Conclusão}

A metodologia alicerçada no desenvolvimento de atividades educativas coletivas de PAAS, proposta no Instrutivo foi uma boa estratégia. Ela impulsionou a organização e a concretização do processo de trabalho da equipe de NASF-AB estudada, bem como o comprometimento dos gestores e profissionais que atuam no NASF-AB e nas equipes de ESF com a proposta, além dos usuários desses serviços. Ademais, a atividade de educação permanente contribuiu para a qualificação das equipes no desenvolvimento das atividades de promoção da saúde e de PAAS.

O desenvolvimento das atividades coletivas de PAAS favoreceram a integração de forças de trabalho de profissionais de diferentes categorias, propiciando o exercício da interdisciplinaridade, o fortalecimento da equipe e a educação compartilhada. Dessa forma, foram criados espaços coletivos de promoção da saúde, erigidos sobre o trabalho colaborativo e visando ao cuidado integral e ao empoderamento dos indivíduos em seu autocuidado.

Contudo, diante dos desafios cotidianos da organização do processo de trabalho na ABS, reforça-se a necessidade de maior envolvimento das equipes da ESF e da gestão na implementação das atividades de educação em saúde, com o objetivo de aperfeiçoar as práticas de atenção à saúde de maneira integrada e colaborativa. Aponta-se, também, a importância de colocar as necessidades de pessoas e famílias no centro das ações de promoção e produção do cuidado à saúde. 


\section{ANÁLISIS DEL TRABAJO EN EQUIPO MULTIPROFESIONAL PARA ACCIONES DE ALIMENTACIÓN Y NUTRICIÓN EN LA ATENCIÓN BÁSICA}

Resumen El estudio analizó el proceso de trabajo de los profesionales de un Núcleo Ampliado de Salud de la Familia en la Atención Básica en la implantación de actividades educativas colectivas de promoción de la alimentación adecuada y sana. Utilizamos el método del abordaje cualitativo, basado en un estudio piloto de un ensayo comunitario controlado y aleatorizado, con la participación de seis profesionales. Las entrevistas siguieron un guion semiestructurado. Se empleó el análisis de contenido para revelar los discursos de los participantes. Tres categorías han emergido: integración del equipo como el eje propulsor del proceso de trabajo; educación liberadora y compromiso como ejes norteadores para la implantación de las actividades colectivas de alimentación sana; y los retos a la implementación de las actividades educativas de alimentación sana. Los resultados demuestran que la metodología de grupo propuesta por el Ministerio de Salud es una buena estrategia para la organización y conducción del proceso de trabajo. Además, favoreció la integración de fuerzas de trabajo de profesionales de distintas categorías, resultando en el fortalecimiento del equipo en el ejercicio de la interdisciplinaridad y en la creación de espacios colectivos de intercambios, de cuidado y de empoderamiento de los individuos asistidos.

Palabras clave promoción de la salud; educación en salud; alimentación; atención primaria de salud

\section{Colaboradores:}

Aline Cristine Souza Lopes foi responsável pela elaboração do projeto, seleção dos participantes, coleta e análises dos dados e redação do artigo. Katiusse Rezende-Alves participou da análise dos dados, da revisão e redação do artigo. Caroline Schilling Soares, Kelly Alves de Magalhães, Larissa Ferraz Morelli e Rayane Jeniffer Rodrigues Marques participaram da coleta e análises dos dados e redação do artigo

\section{Financiamento}

Pesquisa financiada pelo Ministério da Saúde por meio da Organização Panamericana de Saúde (OPAS) e Fundação de Amparo à Pesquisa de Minas

Gerais (FAPEMIG).

Declaramos ausência de conflitos de interesse. 


\section{Referências}

ALVES, Lucia H. S.; BOEHS, Astrid. E.; HEIDEMANN, Ivonete T. S. B. A percepção dos profissionais e usuários da estratégia de saúde da família sobre os grupos de promoção da saúde. Texto \& Contexto Enfermagem, Florianópolis, Santa Catarina, v. 21, n. 2, p. 401-408, 2012.

BARDIN, Laurence. Análise de conteúdo. 5. ed. Lisboa, Portugal: Edições 70, 2009.

BORGES, Silier A. C.; PORTO, Priscila N. Por que os pacientes não aderem ao tratamento? Dispositivos metodológicos para a educação em saúde. Saúde em Debate, Rio de Janeiro, v. 38, n. 101, p. 338-346, 2014.

Brasil. Ministério da Saúde. Secretaria de Atenção à Saúde. Departamento de Atenção Básica. Política Nacional de Alimentação e Nutrição. 1. reimpr. Brasília: Ministério da Saúde, 2013.

BRASIL. Ministério da Saúde. Secretaria de Vigilância em Saúde. Secretaria de Atenção à Saúde. Política Nacional de Promoção da Saúde. 3. ed. Brasília: Ministério da Saúde, 2010.

BRASIL. Ministério da Saúde. Portaria $G M n^{\circ} 154$, de 24 de janeiro de 2008. Cria os Núcleos de Apoio à Saúde da Família-NASF. Brasília, 2008.

BRASIL. Ministério da Saúde. Universidade Federal de Minas Gerais. Instrutivo: metodologia de trabalho em grupos para ações de alimentação e nutrição na atenção básica. Brasília: Ministério da Saúde, 2016a.

BRASIL. Ministério da Saúde. Universidade Federal de Minas Gerais. Desmistificando dúvidas sobre alimentação e nutrição: material de apoio para profissionais de saúde. Brasília: Ministério da Saúde, 2016b.

BRASIL. Ministério da Saúde. Universidade Federal de Minas Gerais. Na cozinha com as frutas, legumes e verduras. Brasília: Ministério da Saúde, 2016c.
BRASIL. Ministério da Saúde. Secretaria de Atenção à Saúde. Coordenação-Geral da Política de Alimentação e Nutrição. Guia alimentar para a população brasileira: promovendo a alimentação saudável. Brasília, Ministério da Saúde, 2014a.

BRASIL. Ministério da Saúde. Secretaria de Atenção à Saúde. Departamento de Atenção Básica. Estratégia Saúde da Família. Brasília: Ministério da Saúde, 2012.

BRASIL. Ministério da Saúde. Secretaria de Atenção à Saúde. Departamento de Atenção Básica. Núcleo de Apoio à Saúde da Família: ferramentas para a gestão e para o trabalho cotidiano: volume 1. Brasília: Ministério da Saúde, 2014b. (Cadernos de Atenção Básica, n. 39).

BRASIL. Ministério da Saúde. Portaria $n^{o}$ 2.436, de 21 de setembro de 2017. Estabelece a revisão de diretrizes da Política Nacional de Atenção Básica (PNAB) no âmbito do Sistema Único de Saúde (SUS). Brasília: Ministério da Saúde, 2017.

CAMPOS, Kátia F. C.; SENA, Roseni R.; SILVA, Kênia L. Educação permanente nos serviços de saúde. Escola Anna Nery, Rio de Janeiro, v. 21, n. 4, e20160317, 2017.

COSTA, Juliana P. et al. Resolubilidade do cuidado na atenção primária: articulação multiprofissional e rede de serviços. Saúde em Debate, Rio de Janeiro, v. 38, n. 103, p. 733-743, 2014.

ERDMANN, Alacoque L. et al. Gestão das práticas de saúde na perspectiva do cuidado complexo. Texto \& Contexto Enfermagem, Florianópolis, v. 15, n. 3, p. 483-491, set. 2006.

FORTUNA, Cinira M. et al. O trabalho de equipe no programa de saúde da família: reflexões a partir de conceitos do processo grupal e de grupos operativos. Revista Latino-Americana 
de Enfermagem, Ribeirão Preto SP, v. 13, n. 2, p. 262-268, 2005.

MATUDA, Caroline G. et al. Colaboração interprofissional na Estratégia Saúde da Família: implicações para a produção do cuidado e a gestão do trabalho. Ciência \& Saúde Coletiva, Rio de Janeiro, v. 20, n. 8, p. 2.511-2.521, 2015.

MENDONÇA, Raquel D.; LOPES, Aline C. S. The effects of health interventions ondietary habits and physical measurements. Revista da Escola de Enfermagem da USP, São Paulo, v. 46 , p. 573-579, 2012.

MENDONÇA, Fernanda F.; NUNES, Elisabete F. P. A. Atividades participativas em grupos de educação em saúde para doentes crônicos. Cadernos Saúde Coletiva, Rio de Janeiro, v. 22, n. 2, p. 200-204, 2014.

MICCAS, Fernanda L.; BATISTA, Sylvia H. S. S. Educação permanente em saúde: metas- síntese. Revista de Saúde Pública, São Paulo, v. 48, n. 1, p. 170-185, fev. 2014.

MINAYO, Maria C. S. O desafio do conhecimento: pesquisa qualitativa em saúde. 13. ed. São Paulo: Hucitec, 2013. 407 p.

QUEIROZ, Maria V. O. et al. Grupo de gestantes adolescentes: contribuições para o cuidado no pré-natal. Revista Gaúcha de Enfermagem, Porto Alegre, RS, v. 37, e2016-0029, 2016.

RICHARDSON, Roberto J. et al. Pesquisa social: métodos e técnicas. 3. ed. São Paulo: Editora Atlas, 1999.

SAPORETTI, Gisele M.; MIRANDA, Paulo S. C.; BELISÁRIO, Soraya A. O profissional de educação física e a promoção da saúde em Núcleos de Apoio à Saúde da Família. Revista Trabalho, Educação e Saúde, Rio de Janeiro, v. 14 n. 2, p. 523-543, 2016.

\section{Errata}

Trabalho, Educação e Saúde, 2023, v.21, ISSN 1981-7746

https://doi.org/10.1590/1981-7746-v18nle0024172

e-location: 00241204

No artigo Análise do trabalho em equipe multiprofissional para ações de alimentação e nutrição na atenção básica, com número DOI: https://doi.org/10.1590/1981-7746sol00241, publicado no periódico Trabalho Educação e Saúde, v. 18(1):e0024172, na página 15, disponível em: https:/www.scielo.br/j/tes/a/c8bGmyHvhgKmBz73dQprKcN/?format=pdf\&lang =pt.

Onde se lia: "Pesquisa financiada pelo Ministério da Saúde por meio da Organização Panamericana de Saúde."

Leia-se: "Pesquisa financiada pelo Ministério da Saúde por meio da Organização Panamericana de Saúde (OPAS) e Fundação de Amparo à Pesquisa de Minas Gerais (FAPEMIG)". 